silica (9). The possibility remains that catalytic activity is due to very small gold particles which could not be sensed by the techniques we employed. Incidentally, the range of gold particle sizes that we have observed encompasses that in which colloid gold is blue in colour (8); particles larger than about $200 \AA$ usually appear red, and the mauve colour of our catalysts is consistent with the presence of particles both greater and smaller than this value.

\section{Transmutation of Catalytic Properties}

We have seen that the catalytic properties of gold as revealed by our work resemble somewhat those of platinum. If the postulate that these properties are due to very small gold particles is correct, then it means we can alter the catalytic activity and specificity of metals simply by changing their crystallite size. Other evidence supports this idea. Very small platinum particles containing only six atoms contained in a zeolite cage behave more like iridium in some reactions of hydrocarbons (13), and the activity of palladium in a zeolite resembles that expected for rhodium in hydrogenation of benzene (14). The explanation proposed is that very small supported metal crystallites become electron deficient, and hence electronically similar to the metal to their left in the Periodic Table, by donation of electrons from metal to the support. Thus sufficiently small particles may have their catalytic properties transmuted, so that gold resembles platinum, platinum resembles iridium and palladium resembles rhodium. Since catalysis, like politics, is 'the art of the possible' (15), and since evidence for transmutation exists, much more attention should be given to the study of the catalytic potentiality of gold, a subject which has lain dormant for so long.

\section{References}

1 R. J. Mikovsky, M. Boudart and H. S. Taylor, f. Am. Chem. Soc., 1954, 76, 3814

2 M. Boudart and L. D. Ptak, 7. Catalysis, 1970, 16, 90; D. D. Eley and D. R. Rossington, "Chemisorption", ed. W. E. Garner, Butterworths (London), 1957, 137. R. P. Chambers and M. Boudart, $\mathcal{F}$. Catalysis, 1966, 5, R. $P$.

3 B. M. W. Trapnell, Proc. Roy. Soc., 1953, A218, 566; R. Culver, J. Pritchard and F. Tompkins, Proc. 2nd Internat. Congress Surface Activity, 1957, 2, 243; H. Wise and K. M. Sancier, $\mathscr{F}$. Catalysis, 1963, 2, 149

4 B. J. Wood and H. Wise, 7 . Catalysis, 1966, 5, 135 ; R. S. Yolles, B. J. Wood and H. Wise, $\mathcal{F}$. Catalysis, 1971 , 21, 66

5 M. Byrne and A. T. Kuhn, F. Chem. Soc. Faraday I, 1972681898

6 W. M. H. Sachtler and N. H. de Boer, F. Phys. Chem., $1960,64,1579$; W. M. H. Sachtler and J. Fahrenfort, Actes 2 me Congres Internat. Catalyse, Edn. Technip, Paris, $I, 1961,831$; G. Parravano, 7. Catalysis, 1970, 18, 320

7 R. P. Chambers and M. Boudart, $\mathcal{F}$. Catalysis, 1966, 5, 517; G. C. Bond, Gold Bull., 1972, 5, (1), 11

$8 \mathrm{~J}$. Turkevich, J. Hillier and P. C. Stevenson, Disc. Faraday Soc., 1951, 11, 55

9 T. A. Dorling, C. J. Burlance and R. L. Moss, $\mathcal{F}$. Catalysis, 1968, 12, 207

10 G. C. Bond, P. A. Sermon, G. Webb, D. A. Buchanan and P. B. Wells F. Chem. Soc., Chem. Comm., 1973, 444

11 G. C. Bond, J. J. Phillipson, P. B. Wells and J. M. Winterbottom, Trans. Faraday Soc., 1964, 60, 1847

12 S. Kishimoto and N. Migaki, F. Phys. Chem., 76, (13), 1907; G. C. Bond, Gold Bull., 1972, 5, (4), 89

13 R. A. Dalla Betta and M. Boudart, Proc. 5th Internat. Congress Catalysis 1972, 1329

14 F. Figueras, R. Gomez and M. Primet, Paper presented at 3rd Internat. Conf. Molecular Sieves, September, 1973

15 D. A. Dowden, Lecture to Society of Chemical Industry in London, 1973

\title{
Selecting Gold Pastes for Thick Film Circuits
}

Hybrid integrated circuits produced by the thick film process are relatively inexpensive to make and have achieved remarkable success for a number of years. An account of the technology of the gold and gold alloy pastes that are screen printed and fired on to the ceramic substrates, recently given in this journal by R. G. Finch (1), showed that no one conductor formulation offers all the desirable properties, and that a large number of proprietary compositions has been developed to meet specific requirements.

Many of these pastes have already demonstrated their usefulness in complex multi-layer interconnection arrays, but others have not yet been available for long enough to establish their capabilities.

Successful multi-layer fabrication is, however, critically dependent upon the selection of an appropriate conductor paste in combination with a dielectric paste, and a useful study of this problem has been reported in a joint paper by Karel Kurzweil, of Société Honeywell Bull, and James Loughran, of General Electric (2). Specially designed test panels were pre- pared so as to simulate as closely as possible actual multi-layer material and processing conditions and their performance data were established over a range of conductor compositions and dielectrics, the main objective being to find a dependable combination for processing moderate quantities of arrays.

Although the investigation disclosed some properties of both gold conductors and dielectrics that were less than ideal, it did yield a good working combination. The conductivity of a number of gold preparations was found to be quite adequate, approaching that of the bulk metal, while their rheology was also acceptable. Because of its ease of printing, high conductivity, good resolution and compatibility with most dielectrics, a product identified as EMCA $212 \mathrm{~B}$ gold was selected as the most satisfactory and reliable.

\section{References}

1 R. G. Finch, Gold Bulletin, 1972, 5, (2), 26

2 K. Kurzweil and J. Loughran, Solid State Technol., 1973, 16, (5), 36 